\title{
A ILEGALIDADE DO PRAZO DECADENCIAL PARA REQUERER O SEGURO-DESEMPREGO
}

\section{THE ILLEGALITY OF THE APPLICATION OF LACHES REGARDING UNEMPLOYMENT INSURANCE}

\author{
Julio Pinheiro Faro Homem de Siqueira \\ $1^{\circ}$ Juizado Especial Federal de Volta Redonda (Volta Redonda, RJ, Brasil) \\ Victor Roberto Corrêa de Souza \\ Tribunal Regional Federal da $2^{\mathrm{a}}$ Região (Rio de Janeiro, RJ, Brasil) \\ Recebimento: 28 jun. 2019 \\ Aceitação: 27 jul. 2020
}

\begin{abstract}
Como citar este artigo / How to cite this article (informe a data atual de acesso / inform the current date of access):
SIQUEIRA, Julio Pinheiro Faro Homem de; SOUZA, Victor Roberto Corrêa de. A ilegalidade do prazo decadencial para requerer o seguro-desemprego. Revista da Faculdade de Direito UFPR, Curitiba, v. 65, n. 2, p. 9-30, maio/ago. 2020. ISSN 2236-7284. Disponível em: https://revistas.ufpr.br/direito/article/view/67642. Acesso em: 31 ago. 2020. DOI: http://dx.doi.org/10.5380/rfdufpr.v65i2.67642.
\end{abstract}

\section{RESUMO}

Este artigo é resultado de uma pesquisa sobre um tema muito específico que não é enfrentado pela doutrina, mas que divide a jurisprudência federal. Trata-se da análise da legalidade do prazo decadencial para requerer seguro-desemprego. O referido prazo foi estabelecido, no ordenamento jurídico brasileiro, por meio de um ato administrativo normativo e, portanto, de natureza infralegal, para limitar o exercício de um direito social fundamental. A questão de fundo que se coloca é: Pode a legislação secundária restringir o exercício de um direito constitucionalmente previsto? A resposta extraída do próprio texto constitucional brasileiro é pela impossibilidade, porque é expressamente prevista a necessidade de lei. Ademais, o mesmo texto prevê que o exercício do poder normativo depende de autorização da lei que ele pretende regulamentar, razão pela qual sua atuação é limitada. Com isso, surge o problema que orientou a pesquisa: - A lei que rege o segurodesemprego autorizou a fixação, por ato administrativo normativo, de prazo decadencial para requerer o benefício? Na doutrina, encontrou-se um único artigo a enfrentar o questionamento, enquanto na jurisprudência foram encontrados dois entendimentos divergentes. O objetivo da pesquisa foi, então, verificar a validade da hipótese pressuposta de resposta, de que o prazo é ilegal. Com isso, fez-se o levantamento da legislação, da doutrina e da jurisprudência sobre o tema, mediante o uso do método descritivo, para, em seguida, com base no método hipotético-dedutivo, analisar a validade dos argumentos da tese da legalidade, demonstrando-se o acerto da tese da ilegalidade.

\section{PALAVRAS-CHAVE}

Direito administrativo. Direitos fundamentais. Seguro-desemprego. Prazo decadencial. Poder regulamentador.

\section{ABSTRACT}

This paper is the result of a research on a very specific issue, which is not faced by doctrine, but divides the Brazilian federal case law. It is the analysis of the legality of laches regarding 
unemployment insurance. Such laches was established, in Brazilian legal order, by means of a normative administrative act (infralegal nature) to limit the exercise of a fundamental social right. Considering this, the background question is: - Can secondary legislation restrict the exercise of a constitutionally provided right? The answer given by the same constitutional text is negative, since it is expressly required the need for a law. Therefore, the Brazilian Constitution also provides that the normative acts' exercise must be authorized by the law that it intent to regulate, being its performance limited. Thereat, the problem that guided this research arises: — Did the law ruling the unemployment insurance authorize the application of laches by secondary legislation? In doctrine a single work on this issue was found, while the courts diverge. The purpose of the research was, then, checking the validity of the assumed hypothesis of response that this laches is illegal. Therewith, a short survey of legislation, doctrine and case law was carried out, by means of descriptive method, to, employing hypothetical-dialectical method, check validity of the arguments of the legality thesis, thus demonstrating the correctness of the illegality thesis.

\section{KEYWORDS}

Administrative law. Fundamental rights. Unemployment insurance. Application of laches. Regulatory power.

\section{INTRODUÇÃO}

O Conselho Deliberativo do Fundo de Amparo ao Trabalhador (CODEFAT) editou em 2005 a Resolução 467, cujo artigo 14 fixou o prazo decadencial de 120 dias para o trabalhador requerer o seguro-desemprego. Trata-se, à evidência, de restrição a exercício de direito constitucionalmente previsto estabelecida por ato infralegal, o que, em princípio, viola o texto constitucional (art. 5 , II, CRFB/1988).

O direito fundamental, na hipótese, é o seguro-desemprego, um benefício integrante do sistema securitário social brasileiro, garantido pelo texto constitucional (arts. $7^{\circ}$, II, e 201, III, CRFB/1988) e regulamentado pela Lei 7.998/1990, a qual não prevê prazo para o requerimento do benefício nem autoriza, expressa ou tacitamente, que seja fixado prazo por ato administrativo. Aliás, há órgãos fracionários de tribunais regionais federais (TRFs) que adotam essa perspectiva, porém seus acórdãos são sempre reformados em sede de recurso especial.

É que o Superior Tribunal de Justiça (STJ), a Turma Nacional de Uniformização dos Juizados Especiais Federais (TNU) e órgãos fracionários de TRFs, ao decidirem sobre o caso, firmaram, em sentido contrário, entendimento de que o prazo decadencial observa a regra da legalidade, sob o argumento de que há autorização do legislador para que a restrição seja fixada por ato administrativo.

Portanto, há dois entendimentos divergentes, mas tão somente um deles é adequado constitucionalmente. Logo, a importância deste ensaio está em apurar quais os argumentos que levaram o STJ, a TNU e alguns órgãos do TRF1 e TRF3 a entender pela legalidade, bem como aqueles 
que conduziram outros órgãos do TRF1 e TRF3 e o TRF2, TRF4 e TRF5 a concluir pela ilegalidade (seção 1). A partir desses levantamentos, realiza-se a discussão dos argumentos, com o propósito de demonstrar, a partir da legislação, da doutrina e de decisões do Supremo Tribunal Federal (STF) e do STJ sobre o adequado exercício do poder regulamentador, a validade da seguinte tese: — O prazo decadencial de 120 dias para requerer o seguro-desemprego, é tanto ilegal, porque não há autorização legal para que o artigo 14 da Resolução CODEFAT 467/2005 faça a restrição, quanto inconstitucional, porque as restrições ao exercício de direitos fundamentais não podem ser feitas por espécies normativas secundárias (seção 2). Ao final, é apresentada a conclusão (seção 3).

O desenvolvimento do ensaio é feito com base em dois métodos. Na seção 1 é utilizado exclusivamente o método descritivo, ao passo que a análise crítica é feita na seção 2, a qual utiliza o método hipotético-dedutivo, cuja estratégia metodológica permite discutir dialética e dialogicamente as decisões apresentadas.

\section{OS DOIS ENTENDIMENTOS CONFLITANTES}

A análise das decisões proferidas pelo STJ, TNU e TRFs permite, como adiantado na introdução, identificar dois entendimentos conflitantes sobre a questão da legalidade do prazo decadencial para requerer o seguro-desemprego. Em síntese, pode-se afirmar o seguinte. A primeira corrente entende que o prazo decadencial de 120 dias para requerer o benefício, firmado pela Resolução CODEFAT 467/2005, observa a regra da legalidade, uma vez que a Lei 7.998/1990 rebaixou, formalmente, o grau normativo do referido prazo (deslegalização), a fim de que atos infralegais possam criar e modificar o referido prazo. E a segunda corrente, ao contrário, entende que não houve deslegalização, de modo que a referida resolução, ao fixar o prazo decadencial, violou a regra da legalidade, bem como extrapolou os limites do poder regulamentador, redundando em inconstitucionalidade.

As duas subseções seguintes cuidam de descrever os entendimentos e de apresentar exemplos de decisões proferidas em ambos os sentidos.

\subsection{O ENTENDIMENTO PELA LEGALIDADE}

O STJ tem um entendimento, firmado em 2005, com base em um único julgado, proferido pela $2^{\text {a }}$ Turma, de que o prazo decadencial de 120 dias, estabelecido, também em 2005, pela Resolução CODEFAT 467, para requerer o benefício é legítimo (BRASIL, 2005). Segundo se pode 
extrair do inteiro teor, a Lei 7.998/1990 autoriza o Conselho a estabelecer os procedimentos necessários ao recebimento do benefício, podendo editar ato normativo administrativo para suprir situação não prevista na lei, dentro dos limites autorizados por ela própria. Portanto, de acordo com o voto condutor, não devem subsistir acórdãos que se baseiem no argumento da ilegalidade do ato normativo e afastem o prazo decadencial. O julgado era, até o início de abril de 2019, o único encontrado sobre a análise de legalidade do prazo decadencial, mediante pesquisa no site do STJ com os argumentos “prazo”, “seguro-desemprego”, “resolução” e “CODEFAT”. Todos os outros julgados encontrados com esses mesmos argumentos são decisões monocráticas, as quais seguem o entendimento firmado pela $2^{a}$ Turma em 2005, com a fundamentação de que há jurisprudência firme e pacífica e que não há inovação na ordem jurídica (e.g. BRASIL, 2019a). A 2 a Turma reafirmou o seu entendimento da legalidade do prazo em 2019 e em 2020 (BRASIL, 2019b, 2020a). Portanto, todos os recursos especiais que impugnam acórdãos de TRFs que afastam o prazo decadencial em razão do reconhecimento da ilegalidade do prazo decadencial são providos, desde que recebidos.

A TNU, curvando-se ao entendimento do STJ, firmou, em recurso representativo de controvérsia (Tema 62), que “é legal a Resolução n. 467/2005 do CODEFAT que fixa prazo máximo de 120 dias após a data da dispensa para requerer o seguro-desemprego” (BRASIL, 2012a). O mesmo entendimento foi mantido em decisões posteriores da TNU (e.g. BRASIL, 2018a), que reformaram acórdãos de Turmas Recursais regionais que, apesar de conhecerem a posição da TNU, adotam a perspectiva de que a Resolução CODEFAT extrapolou o poder regulamentador. A análise dos acórdãos da TNU revela que os julgadores se basearam na “jurisprudência dominante” do STJ, firmada em dois acórdãos, um proferido pela $2^{\mathrm{a}}$ Turma (BRASIL, 2005) e outro monocraticamente, embora a TNU aponte sua prolação pela $1^{a}$ Turma do STJ (BRASIL, 2010). Portanto, um único julgado colegiado do STJ, firmado por uma de suas turmas, que por isso mesmo não pode ser considerado precedente, determinou a fixação da tese da TNU de que, no caso, o poder regulamentador foi adequadamente exercido, mormente em razão da existência, no caso, da deslegalização. Esse fenômeno significa, simplesmente, que a Lei 7.998/1990 rebaixou, formalmente, o grau normativo do estabelecimento do prazo decadencial, permitindo que ele seja fixado ou modificado por regulamento.

Os entendimentos do STJ e da TNU são utilizados como parâmetros por alguns órgãos fracionários de TRFs, podendo-se listar, entre eles, como atualmente adeptos da tese de legalidade os seguintes: $2^{\mathrm{a}}$ Turma do TRF1 (BRASIL, 2018b), $2^{\mathrm{a}}$ Turma Especializada do TRF2 (BRASIL, 2019d), as $7^{\mathrm{a}}$ e $8^{\mathrm{a}}$ Turmas do TRF3 (BRASIL, 2020d, 2019c). 


\subsection{O ENTENDIMENTO PELA ILEGALIDADE}

A $1^{\text {a }}$ Turma do TRF1 entende que o prazo é ilegal, uma vez que a Lei 7.998/1990 não firmou restrição temporal máxima quanto à realização de requerimento do seguro-desemprego, mas apenas que o pedido deve ser feito a partir do sétimo dia subsequente à rescisão formal do contrato de trabalho, de modo que a Resolução do CODEFAT extrapolou os limites do poder normativo (BRASIL, 2020b). No TRF2, as $1^{\mathrm{a}}$, 5 ${ }^{\mathrm{a}}, 6^{\mathrm{a}}$ e $7^{\mathrm{a}}$ Turmas Especializadas têm o mesmo entendimento e acrescentam, ainda, que se o legislador optou por não fixar prazo decadencial, não pode o administrador, por resolução, fazê-lo, sob pena de ilegalidade, e também de inconstitucionalidade, por ofensa aos artigos 5º II, e 37, caput, da CRFB/1988 (BRASIL, 2018c, 2018d, 2018e, 2018f). A 10 $0^{\text {a }}$ Turma do TRF3 entende, atualmente e pelas mesmas razões, que o prazo é ilegal (BRASIL, 2020c). O entendimento de que a restrição é ilegal é apoiado também pelo TRF4, podendo-se encontrar julgados das $3^{\mathrm{a}}$ e $4^{\mathrm{a}}$ Turmas no sentido de que a Resolução CODEFAT cria, sem amparo legal, uma restrição (BRASIL, 2020e, 2020f). Por fim, no TRF5, as $1^{\text {a }}, 2^{\mathrm{a}}$, $3^{\mathrm{a}}$ e $4^{\mathrm{a}}$ Turmas têm entendimento consolidado de que a Resolução CODEFAT 467/2005 inovou restritivamente no ordenamento jurídico brasileiro, criando uma limitação ao exercício de direito, que não tem espeque na Lei 7.998/1990 (BRASIL, 2019e, 2018g, 2018h, 2012b).

Portanto, pode-se concluir que apenas nos TRF4 e TRF5 há entendimento pacífico pela ilegalidade do prazo decadencial fixado pela Resolução 467/2005 do CODEFAT. No TRF3 predomina o entendimento pela legalidade, enquanto no TRF2 predomina pela ilegalidade. E, no TRF1, há divisão entre as duas turmas.

\section{DISCUSSÃO SOBRE O ENTENDIMENTO ADEQUADO}

A breve seção anterior apresentou e descreveu os entendimentos conflitantes do STJ, TNU e TRFs sobre a legalidade do prazo decadencial para requerer o benefício de seguro-desemprego. A proposta da presente seção consiste em discutir os argumentos utilizados, na busca pela apuração da validade constitucional (daí falar em entendimento adequado) da hipótese de resposta apresentada já na introdução, com o objetivo de apurar a sua conversão ou não em tese. Nesse sentido, as subseções a seguir apresentadas estão divididas entre: analisar a legislação de regência quanto à previsão de prazo decadencial; identificar a crítica na doutrina sobre o tal prazo; entender a jurisprudência do STF e do STJ quanto aos limites do poder regulamentador; e discutir sobre a tese proposta. 


\subsection{A LEGISLAÇÃO DE REGÊNCIA E A PREVISÃO DE PRAZO DECADENCIAL}

A regulamentação do benefício de seguro-desemprego é principalmente feita pela Lei 7.998/1990, mas há também leis específicas, como a Lei 10.779/2003, regulamentada pelo Decreto 8.424/2015 e que trata sobre o seguro-desemprego para o período de defeso (ou seguro-defeso), e a Lei Complementar 150/2015, que traz regras especiais para o caso do empregado doméstico (arts. 26 a 30).

Em uma pesquisa pela palavra "prazo” nas três mencionadas leis, são encontradas 10 ocorrências na Lei 7.998, nenhuma na Lei 10.779 e 14 na Lei Complementar 150. De todas as ocorrências, nenhuma delas se refere ao prazo decadencial para o requerimento do benefício. Fez-se, também, a pesquisa pelas palavras “requerer” e suas variantes, razão pela qual se utilizou do radical “requer-”, tendo-se encontrado três ocorrências na lei de 1990, quatro na de 2003 e seis na de 2015, sendo que apenas duas das 13 têm relação direta com o prazo para requerer o benefício e se encontram nas leis de 1990 e 2015.

A ocorrência encontrada na Lei 7.998 está contida no artigo 6º com a redação a seguir: “o seguro-desemprego é direito pessoal e intransferível do trabalhador, podendo ser requerido a partir do sétimo dia subsequente à rescisão do contrato de trabalho”. A partir do texto pode-se extrair a regra de que o trabalhador deve esperar no mínimo sete dias para requerer seguro-desemprego, prazo que deve ser contado a partir do dia seguinte ao da data da rescisão contratual. Logo, para fazer o requerimento é necessário aguardar um prazo de sete dias corridos, não havendo nenhuma prescrição legal sobre um prazo máximo.

O fato de o caput e o $\S 5^{\circ}$ do artigo $4^{\circ}$ da Lei 7.998 preverem que o benefício será concedido por período máximo variável de três a sete meses não autoriza, a propósito, concluir haver um prazo máximo para formular o requerimento. A única regra obstativa relativa ao requerimento decorre da interpretação conjugada dos artigos $3^{\circ}, 4^{\circ}$, $\S 1^{\circ}$, e $7^{\circ}$, todos da mencionada lei. De acordo com os textos normativos dos três artigos indicados, o seguro-desemprego não será pago se, na data do requerimento, o interessado possuir renda própria, de qualquer natureza (o que inclui benefícios previdenciários), suficiente à manutenção de si próprio e sua família. Logo, como o segurodesemprego é um auxílio financeiro temporário ao trabalhador desempregado (art. $2^{\circ}$ ), logicamente inexiste direito retroativo à sua percepção, salvo se comprovada a manutenção do desemprego e se não ultrapassado o prazo prescricional para o recebimento dos valores. Isso, todavia, não tem relação com o prazo decadencial objeto do presente estudo. 
Além dessas análises, é também importante sublinhar que, em momento algum, o legislador ordinário transferiu ao poder regulamentador, nem implicitamente, a fixação de um prazo máximo para requerer o benefício. A leitura atenta revela apenas a previsão de que o Poder Executivo deve regulamentar a Lei 7.998 em até 90 dias após a publicação (art. 30), o que não foi cumprido.

Ainda no que se refere à Lei 7.998, como ela não possui regulamento, é necessário ter atenção ao seu artigo 19, que elenca as competências do CODEFAT, órgão colegiado responsável pela gestão do fundo de amparo ao trabalhador (FAT), preceituando, especificamente, no inciso V, que é competência do Conselho "propor o aperfeiçoamento da legislação relativa ao segurodesemprego e ao abono salarial e regulamentar os dispositivos desta Lei no âmbito de sua competência”. Note o verbo que inaugura o inciso: propor, isto é, sugerir, apresentar, oferecer como opção, submeter à apreciação, o que não se confunde com os significados decorrentes dos verbos alterar e criar. Portanto, pela Lei 7.998, o Conselho é órgão de execução, não de criação ou de modificação.

O inciso V do artigo 19 da Lei 7.998 serve como fundamento para a Resolução CODEFAT 467/2005, como consta de seu cabeçalho: “O Conselho Deliberativo do Fundo de Amparo ao Trabalhador - CODEFAT, no uso das atribuições que lhe confere o inciso V do art. 19 da Lei $n^{0}$ 7.998, de 11 de janeiro de 1990, resolve”. O propósito da Resolução decorre de seu artigo $1^{0}$ : “estabelecer critérios relativos à integração das ações de concessão do seguro-desemprego e de assistência aos trabalhadores dispensados face às alterações introduzidas na Lei 7.998/90 e na legislação trabalhista”. Novamente, note que nada há neste dispositivo que direcione a espécie normativa infralegal à competência de estabelecer prazos, que, a propósito, não são critérios, mas períodos de tempo.

A própria Resolução CODEFAT 467/2005 traz, no entanto, no caput de seu artigo 14, o seguinte texto normativo: "os documentos de que trata o artigo anterior deverão ser encaminhados pelo trabalhador a partir do $7^{\circ}$ (sétimo) e até o $120^{\circ}$ (centésimo vigésimo) dias subsequentes à data da sua dispensa”. A norma que se extrai é que: se o trabalhador for dispensado, terá um prazo de até 120 dias, contados da dispensa, para requerer o seguro-desemprego. A se considerar o objetivo anunciado no artigo $1^{\circ}$ da Resolução, é cabível dizer que o artigo 14 contém uma norma intrusa, na mesma acepção dada pelo STF para o chamado “contrabando legislativo” (BRASIL, 2016c).

No que diz respeito ao seguro-defeso, a Lei 10.779 possui um regulamento, editado mais de uma década depois da publicação da lei: o Decreto 8.424/2015. A pesquisa pelo vocábulo "prazo" revela, nesta espécie normativa infralegal, sete ocorrências, das quais duas se referem ao prazo para o requerimento, ambas no artigo $4^{\circ}$, cujo caput estabelece o prazo decadencial: “o prazo para requerer 
o benefício do seguro-desemprego do pescador profissional artesanal se iniciará trinta dias antes da data de início do período de defeso e terminará no último dia do referido prazo”. Trata-se, portanto, de um prazo decadencial em branco ou aberto, que depende da duração do período de defeso. Além disso, das 11 ocorrências encontradas para o radical "requer-" no regulamento, duas dizem respeito ao prazo e estão no mesmo artigo $4^{\circ}$, caput.

Todavia, em nenhum dos casos o poder regulamentador tem respaldo da Lei 10.779 para fixar tais prazos; ainda que haja certa lógica, o intérprete, como o regulamentador, não pode criar, onde a lei não o fez, obrigações e restrições ao exercício de direitos fundamentais. Aqui também é válida a interpretação feita aos artigos $3^{\circ}, 4^{\circ}$, § $1^{\circ}$, e $7^{\circ}$ da Lei 7.998 sobre não ser devido o seguro caso o beneficiário potencial não mais se encontrar desempregado. No caso do seguro-defeso, a Lei 10.779 restringe o recebimento apenas ao período em que vigente o defeso (art. $1^{\circ}$, $\S \S 2^{\circ}$ a $4^{\circ}$ ), mas isso não significa que há um prazo decadencial, uma vez que toda restrição ao exercício de direitos deve ser explícita.

A Lei Complementar 150, diferentemente das Leis 7.998 e 10.779, fixa um prazo decadencial, expressamente, como se extrai de seu artigo 29: “o seguro-desemprego deverá ser requerido de 7 (sete) a 90 (noventa) dias contados da data de dispensa”. Logo, pode-se afirmar que tão somente no caso do empregado doméstico há prazo decadencial legalmente estabelecido.

Em conclusão parcial, o que se tem é que: (i) as Leis 7.998 e 10.779 não fixam prazos decadenciais para o requerimento do seguro-desemprego; (ii) as Leis 7.998 e 10.779 não delegam ao Executivo a competência para estabelecer referidos prazos; (iii) o Decreto 8.424/2015 e a Resolução CODEFAT 467/2005 fixam prazos decadenciais para o requerimento do benefício; e (iv) a Lei Complementar 150 é a única que estabelece prazo decadencial, o qual se restringe ao requerimento do benefício pelo empregado doméstico desempregado.

\subsection{A DOUTRINA SOBRE O PRAZO DECADENCIAL}

A pesquisa pela análise doutrinária acerca do prazo decadencial para requerer o benefício do seguro-desemprego é frustrante. Nos livros de direito do trabalho em que há o tratamento do instituto securitário, não é feita menção ao prazo da Resolução CODEFAT 467, como se pode extrair de Romar (2018), Leite (2019a, 2019b), Pamplona Filho (2020), Cairo Jr. (2019), Moura (2016) e Nascimento (2014), por exemplo, e salvo em Martinez (2020) e Souza Júnior (2015), em que existe menção, mas sem qualquer apreciação crítica. Também não há nenhuma tese ou dissertação no repositório da Capes de Teses e Dissertações a respeito dessa análise, seja com o argumento “codefat”, ou com ele 
associado aos argumentos "seguro-desemprego" e/ou "prazo decadencial”. No mesmo sentido, a pesquisa de artigos sobre a resolução não retornou resultados no SciELO nem no Portal de Periódicos da Capes. Na pesquisa feita no Google foi encontrado um único trabalho publicado por Demo e Somariva (2006), que analisa criticamente a questão, tendo os autores concluído que os prazos decadenciais estabelecidos pelo CODEFAT em suas resoluções para o requerimento tanto do segurodesemprego quando do seguro-defeso são ilegítimos.

\subsection{OS LIMITES DO EXERCÍCIO DO PODER REGULAMENTADOR}

O STF não possui nenhum julgado sobre a questão do presente estudo, mesmo porque não tem competência constitucional para realizar controle de legalidade de atos infralegais (BRASIL, 2015a), salvo casos específicos de controle concentrado de constitucionalidade. No entanto, como a dúvida posta na introdução diz respeito aos limites do poder regulamentador e estes têm previsão no texto constitucional, é possível analisar por esse viés e apurar se o STF entenderia, mantendo a coerência de seu entendimento, pela ilegalidade ou não do prazo decadencial em questão.

O entendimento consolidado do STF é de que há exercício abusivo do poder regulamentador quando são expedidos atos normativos que atuam praeter legem ou contra legem. O Plenário já decidiu que a competência regulamentadora "não se reveste de suficiente idoneidade jurídica que lhe permita restringir direitos ou criar obrigações”, domínio que é “constitucionalmente reservado ao âmbito de atuação material da lei em sentido formal” (BRASIL, 2006). Portanto, não cabe ao administrador público colmatar lacunas nem legislar onde o legislador não legislou. As Turmas, por sua vez, firmaram, em consonância com o Tribunal Pleno, que o poder regulamentador não se confunde com a função legislativa, constituindo-se, na verdade, em função normativa (BRASIL, 2009), razão pela qual "atos administrativos normativos não podem ultrapassar os limites da lei que visam regulamentar” (BRASIL, 2015b).

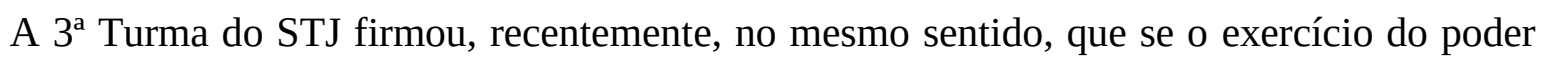
regulamentador com a edição de ato normativo respeitar os limites da lei que autoriza a sua existência, não haverá ilegalidade (BRASIL, 2020g). E a avaliação a respeito de se há extrapolação ou violação da hierarquia normativa e da reserva legal é competência, segundo firmado pela $2^{\mathrm{a}}$ Turma do STJ, do STF (BRASIL, 2019f). Todavia, é esse mesmo órgão que, provocado, decide se houve exorbitância ou não, conforme se extrai dos julgados citados na seção anterior a respeito do entendimento pela legalidade do prazo decadencial para o requerimento do seguro-desemprego. Por fim, a $1^{\text {a }}$ Seção do STJ firmou, em sede de recurso repetitivo (Tema 998), o mesmo entendimento adotado pela $3^{\text {a }}$ Turma 
e pelo STF, de que a edição de ato administrativo normativo extrapola os limites do poder regulamentador quando restringe ilegalmente direito do indivíduo; no caso concreto, a proteção previdenciária dada ao trabalhador sujeito a condições que prejudicam a sua saúde ou integridade física (BRASIL, 2019g).

Portanto, pode-se dizer que o entendimento da jurisprudência brasileira, levando-se em conta acórdãos do STF e do STJ, é que há exercício abusivo do poder normativo quando o respectivo ato administrativo regulamenta situação prevista de outra forma na lei (contra legem), ou situação silenciada/não autorizada expressamente pela lei (praeter legem).

\subsection{DISCUSSÃO SOBRE A TESE}

A partir das três premissas estabelecidas nas três subseções acima e com base nos dois entendimentos divergentes apresentados na primeira seção deste estudo, é chegada a hora de discutir sobre a tese proposta que intitula, inclusive, este trabalho.

Os direitos fundamentais são limitados. A limitação geralmente é percebida a partir da observação de que o direito de uma pessoa vai até onde começa o direito de outra. Com efeito, direitos limitam direitos, ou, mais propriamente, o dever de respeitar o direito do próximo funciona como obstáculo para o exercício de direitos. É por isso que existem institutos como a legítima defesa, o desforço imediato da posse, as medidas cautelares e as ações judiciais, por exemplo. Todos eles visam assegurar, razão pela qual também são garantias, que, ante o descumprimento do dever de respeito, o direito prevaleça.

Todavia, há um outro tipo de restrição aos direitos fundamentais: o tempo, que pode ser um aliado ou um verdadeiro algoz, a depender de como ele é utilizado. A influência do tempo no mundo jurídico tem, em regra, ao menos três efeitos: promove a aquisição de direitos (prescrição aquisitiva), extingue direitos (decadência) ou promove a perda de oportunidades relacionadas aos direitos [preclusão e prescrição (extintiva)]. O presente estudo enfrenta esse tipo de limitação temporal, mais especificamente a decadência.

É, no entanto, inadequado desvincular a decadência da prescrição, o que tenderia a ocorrer se os institutos fossem tratados separadamente. Isso porque, por uma questão de lógica simples, o prazo decadencial não pode ser menor que o prescricional, ou seja, uma pessoa não pode possuir uma pretensão sem ter o direito correspondente, já que não se pode proteger algo inexistente, embora possa possuir esse direito sem ter a oportunidade de exercê-lo. 
Segundo Amorim Filho (1960), a prescrição funciona como limite ao exercício da pretensão (ação) para reclamar uma prestação que restaure um direito, ou seja, esgotado o prazo prescricional, extingue-se a ação. Isso quer dizer que a ação para impedir uma lesão ou fazer com que ela cesse não pode, em regra, ser proposta a qualquer tempo. Extinta a ação, extingue-se a oportunidade relacionada ao direito, a possibilidade de obter uma condenação. Apesar disso, o direito permanece. É aí que entra a decadência, um limitador do exercício de direitos, de maneira que o seu decurso impede que o direito se constitua, isto é, seja exercido. Há, aqui, dois tipos de pretensões; por um lado, as constitutivas afirmam a existência de um direito, por outro, as condenatórias sustam a lesão ou a tentativa de lesão desse direito, podendo-se afirmar, então, que todas as ações condenatórias são constitutivas, mas não o reverso. A conclusão é que a decadência restringe o exercício do direito, que subsiste, na ordem jurídica, como uma triste ou feliz lembrança para o seu titular.

Nesse sentido, para discorrer sobre o instituto da decadência é imprescindível que se entenda a questão da possibilidade de restrição ao exercício de direitos fundamentais, como é o caso do benefício securitário do seguro-desemprego. Toda restrição a um direito é, conforme aponta Edilsom Farias (2000), uma limitação do âmbito de proteção ou pressuposto de fato e que decorre do texto constitucional, seja diretamente, quando o próprio constituinte estabelece a restrição (“é plena a liberdade de associação [...], vedada a de caráter paramilitar”, cf. art. 5º XVII), seja indiretamente, quando o constituinte dá ao legislador autorização para fazê-lo (“é livre o exercício de qualquer [...] profissão, atendidas as qualificações profissionais que a lei estabelecer”, cf. art. 5 , XIII), ou quando autoriza o Legislativo ou o Judiciário a resolver casos de colisão entre direitos ou conflitos entre eles e valores constitucionalmente protegidos.

As possibilidades de restringir o exercício de direitos fundamentais são tão somente as três acima elencadas, não havendo uma quarta. Com elas, o constituinte brasileiro firma que os direitos são tangíveis e limitados, mas sempre quanto ao seu exercício. Embora os especialistas em direitos fundamentais aprofundem a análise dessas restrições, geralmente com a finalidade de apurar se existe um núcleo essencial imexível, a proposta aqui é mais singela e circunscreve-se à seguinte verificação: - Que tipos de instrumentos normativos podem limitar ou restringir o exercício de direitos fundamentais?

A resposta a essa pergunta é aparentemente óbvia, porque o sistema constitucional brasileiro admite a regulamentação, inclusive para restringir, de direitos fundamentais por meio, apenas, de emendas constitucionais, leis, ordinárias e complementares, e medidas provisórias, ou seja, apenas algumas das espécies normativas primárias previstas no texto constitucional (art. 59). Nesse passo, é questão pacífica entre os juristas a existência de uma hierarquia que determina a existência de um 
escalonamento entre normas jurídicas, de modo que umas busquem o seu fundamento de validade nas outras até chegar em uma norma pressuposta fundante, que confere unidade ao ordenamento jurídico, conforme se pode extrair das lições de Kelsen (1986, 1998), Bobbio (1999), Merkl (2004, 2005), Walter (2005), Raz (1974) e Robles (1982), entre outros.

A título de exemplo, imagine-se um ordenamento jurídico hipotético, no qual, além da norma pressuposta fundante, haja normas constitucionais, normas infraconstitucionais ou legais, e normas infralegais. Todas essas normas, salvo a pressuposta, por um motivo lógico, estão registradas (escritas) no ordenamento jurídico e decorrem de iguais espécies normativas. Os especialistas em Teoria Geral do Direito afirmam, pode-se dizer que em uníssono, que as espécies infralegais buscam sua validade nas infraconstitucionais, que, por sua vez, validam-se nas espécies constitucionais, cujo fundamento de validade advém daquela norma pressuposta fundante. É esse entendimento que permite a existência dos controles de legalidade e de constitucionalidade.

De volta à pergunta feita, a resposta que se impõe é a de que o exercício de direitos fundamentais somente pode ser restringido por meio de normas constitucionais ou normas infraconstitucionais, isto é, decorrentes de espécies normativas originárias (no primeiro caso) ou primárias (no segundo), mas não de secundárias (caso das normas infralegais). Com isso, a partir do entendimento, também pacífico, de que a decadência restringe o exercício de direitos fundamentais, é possível, na mesma trilha, afirmar que apenas as espécies normativas originárias e primárias podem fixar prazos decadenciais. Todavia, salta aos olhos a existência de entendimentos firmados na jurisprudência brasileira com entendimento destoante, pelo qual atos infralegais, como resoluções administrativas, têm aptidão legal e, por isso, validade, para estabelecer prazos decadenciais e, assim, limitar o exercício de direitos fundamentais.

Para confirmar a tese proposta, optou-se por analisar e desconstruir os argumentos lançados pela corrente que defende a legalidade da fixação do prazo pela Resolução 467.

O primeiro argumento é o de que a legislação sobre seguro-desemprego autorizou que o prazo fosse fixado por ato administrativo normativo.

O STJ, ao defender o seu entendimento, alega que a autorização decorre do artigo $2^{\circ}$-C, $\S 2^{\circ}$, da Lei 7.998/1990, cabendo ao CODEFAT “estabelecer os procedimentos necessários ao recebimento do benefício” (grifo nosso). Esse dispositivo, no entanto, não diz, em lugar algum, que aquele Conselho pode estabelecer prazos para o exercício de direitos. É dizer, não se pode confundir normas procedimentais, que formalizam um caminho ou rito a ser seguido, com normas materiais, que disciplinam as relações jurídicas entre os sujeitos de direito. No caso do dispositivo em questão, a autorização dada pela lei à Administração Pública é a de que esta disponha sobre o requerimento 
inicial, o trâmite e a decisão final do processo administrativo em que se postula a concessão do seguro. Isso nada tem a ver com a possibilidade de restringir um direito, mediante a criação de um prazo decadencial. Entender o contrário é o mesmo que permitir à Secretaria de Previdência, no exercício de seu poder regulamentador, lançar resolução estipulando um prazo para o requerimento dos demais benefícios previdenciários.

A propósito, é interessante o fato de as decisões da $2^{\mathrm{a}}$ Turma do STJ seguirem pelo caminho da legalidade e, ao mesmo tempo, apontar o seguro-desemprego como um benefício de natureza previdenciária. Isso porque, não só a TNU, em sua Súmula 81 - "não incide o prazo decadencial previsto no art. 103, caput, da Lei n. 8.213/91, nos casos de indeferimento e cessação de benefícios, bem como em relação às questões não apreciadas pela Administração no ato da concessão” -, como o STF, em repercussão geral (Tema 313), decidiram que não se aplica prazo decadencial para a concessão inicial de benefícios previdenciários (BRASIL, 2014). Aliás, a Lei 13.846/2019, contrariando tais orientações, restabeleceu o prazo de 10 anos para o requerimento originário.

Não se desconhece que ambos os entendimentos dizem respeito à aplicabilidade ou não do prazo decenal do artigo 103 da Lei 8.213/1991 ao requerimento do benefício. No entanto, o argumento utilizado para afastar o prazo é inteiramente aplicável ao caso do seguro-desemprego. Como registrou o voto condutor no Tema 313/STF: quanto “ao direito à obtenção de benefício previdenciário, a disciplina legislativa não introduziu prazo algum”, de maneira que se pode dizer que "o direito fundamental ao benefício previdenciário pode ser exercido a qualquer tempo, sem que se atribua qualquer consequência negativa à inércia do beneficiário”. Ora, se, de fato, o segurodesemprego é um benefício previdenciário, então o prazo decadencial para o seu exercício deve, necessariamente, decorrer de previsão legal, do contrário, ele poderá ocorrer a qualquer momento. Por isso é que o prazo nonagesimal da Lei Complementar 150/2015 não possui vício de inconstitucionalidade.

Ademais, a análise da Lei 7.998/1990 permite apontar que, não só o artigo $2^{\circ}$-C, $\S 2^{\circ}$, conforme se encontra nas decisões do STJ, repetidas pela TNU e por alguns dos órgãos fracionários dos TRF1, TRF1 e TRF3, como também o artigo 19, V, conforme se extrai da Resolução CODEFAT 467/2005, não autorizam a Administração Pública a editar resolução que fixe um prazo decadencial, como o próprio legislador, ao criar a Lei 7.998, optou por não fixar prazo máximo algum para a formulação do requerimento, tendo, em seu artigo $6^{\circ}$, firmado apenas um prazo mínimo de espera para realizá-lo.

Portanto, nesse ponto, a resolução é ilegal. 
O segundo argumento é de que a resolução, enquanto decorrência do exercício do poder regulamentador, teve em mira suprir situação não prevista em lei, mas que foram respeitados os limites por ela estabelecidos.

Como já se viu, a Lei 7.998/1990 não estabelece prazo para requerer a concessão do benefício, então, logicamente, não poderia estabelecer limites. O único prazo para o requerimento previsto na lei é, na verdade, um prazo inicial para requerimento, já que o benefício deve ser pedido a partir do sétimo dia subsequente à rescisão contratual (art. $6^{\circ}$ ). Do contrário, o silêncio do legislador parece ser não do tipo lacunoso, esquecido, mas eloquente, proposital, o qual somente pode ser alterado pelo próprio Legislativo, em razão do princípio da separação dos poderes.

Além desse problema de lógica, há outro. O STJ, em sua decisão, utilizada como paradigma, reconhece que a resolução é fruto do poder regulamentador ou normativo da Administração Pública, tendo a mesma função do regulamento. Aliás, segundo Mello (2001), doutrina utilizada pelo relator, o regulamento é ato geral e abstrato cuja única finalidade (estrita finalidade) é produzir disposições operacionais que uniformizem a execução de lei cuja aplicação requeira a atuação da Administração Pública. Ora, se a resolução, assim como o regulamento, tem a função de uniformizar o procedimento para a aplicação da lei, então se pode concluir que ela atua, necessariamente, secundum legem, mas nunca contra legem, para contrariá-la, ou praeter legem, para complementá-la.

A propósito, de acordo com o STF, o Poder Executivo exerce abusivamente o seu poder regulamentador quando atua contra legem ou praeter legem. Por isso, não se pode confundir a função normativa com a legislativa, uma vez que o poder regulamentador deve atuar em consonância com a lei, para operacionalizá-la. Em outros termos, quando o legislador afirma que ao CODEFAT cumpre “estabelecer os procedimentos necessários ao recebimento do benefício”, nada mais confere ao Conselho que a função de aplicar os comandos legais, operacionalizando a lei, não lhe abrindo a oportunidade de inovar na ordem jurídica.

No caso, como deixou registrado o próprio STJ, a Resolução CODEFAT 467/2005 teve como propósito “suprir uma situação não prevista na lei, porém dentro dos limites autorizados pela própria legislação”. Isso significa que a resolução atuou praeter legem e, portanto, tem-se o exercício abusivo do poder regulamentador. Esse exercício só não seria abusivo se, ainda que praeter legem, trouxesse algum benefício ao exercício do direito - o que não é o caso. O mais curioso no entendimento da $2^{\mathrm{a}}$ Turma do STJ é que ela destoa tanto do entendimento da $3^{\mathrm{a}}$ Turma quanto do da

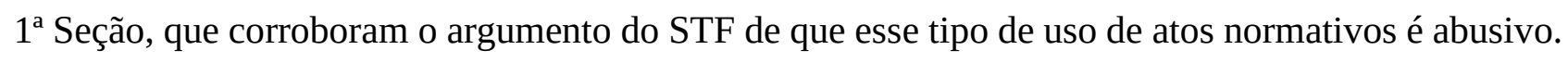

Portanto, também nesse ponto, a resolução é ilegal. 
O terceiro argumento utilizado é o de que, em relação ao prazo decadencial, houve o fenômeno da deslegalização, porque a lei rebaixou a regulamentação da matéria, admitindo sua modificação por regulamento.

A TNU é que se utiliza dessa argumentação. Segundo Gomes Canotilho (1993, p. 915), doutrina utilizada pelo relator do Tema 62, o fenômeno da deslegalização ou da degradação do grau hierárquico consiste em que "uma lei, sem entrar na regulamentação da matéria, rebaixa formalmente o seu grau normativo, permitindo que essa matéria possa vir a ser modificada por regulamento”. Logo, para que haja o rebaixamento, é necessário haver uma lei deslegalizadora, o que inexiste. Isso porque a regulamentação material sobre o benefício é feita pela Lei 7.998/1990, cabendo ao CODEFAT tão somente o procedimento administrativo, isto é, a operacionalização da aplicação da lei, o que pode ser feito, tranquilamente, por resolução.

Portanto, aqui também há ilegalidade da resolução.

Em suma, como se pode verificar, os argumentos utilizados pelo STJ, pela TNU e por algumas das Turmas dos TRF1, TRF2 e TRF3 carecem de força, sendo, assim, insubsistentes por si sós. Todavia, os argumentos que os desconstroem não são os únicos, há ainda pelo menos outro que deve ser apresentado.

O entendimento consensual da doutrina e da jurisprudência a respeito da decadência aponta no sentido de que o seu principal efeito é a extinção de um direito. Nesse sentido, por mais que seja sensato estabelecer um prazo para o exercício de um direito, a fim de que este não se eternize, decorre do ordenamento jurídico brasileiro, inclusive do texto constitucional (art. $5^{\circ}$, II), que o exercício de um direito só pode ser extinto mediante as espécies normativas que podem inovar na ordem jurídica (art. 59). E a resolução executiva não é uma delas.

Com isso, pode-se concluir pela inconsistência da tese da legalidade e pela validade da tese defendida no presente estudo.

\section{CONCLUSÃO}

Pode-se afirmar que a tese lançada neste trabalho é válida e concluir com a sua apresentação: - O prazo decadencial de 120 dias para requerer o seguro-desemprego é tanto ilegal, porque não há autorização legal para que o artigo 14 da Resolução CODEFAT 467/2005 faça a restrição, 
quanto inconstitucional, porque restringe o exercício de direito fundamental, o que não pode ser feito por espécies normativas secundárias.

Além da formulação da tese, é necessário que o STF seja provocado de algum modo para se pronunciar não sobre a ilegalidade da Resolução CODEFAT 467/2005, uma vez que não lhe cabe esse controle, mas sobre a possibilidade ou não de, no exercício do poder regulamentador, a Administração Pública restringir direito fundamental que não encontra limitação na lei que o rege e que nela também não encontra autorização para estabelecer a restrição questionada. Os argumentos estão todos postos neste estudo.

\section{REFERÊNCIAS}

AMORIM FILHO, Agnelo. Critério científico para distinguir a prescrição da decadência e para identificar as ações imprescritíveis. Revista da Faculdade de Direito da UFC, Fortaleza, vol. 14, p. 301-351, 1960.

BOBBIO, Norberto. Teoria do ordenamento jurídico. Tradução Maria Celeste Cordeiro Leite dos Santos. 10. ed. Brasília: Editora Universidade de Brasília, 1999.

BRASIL. Conselho Deliberativo do Fundo de Amparo ao Trabalhador. Resolução 467, de 21 de dezembro de 2005. Estabelece procedimentos relativos à concessão do Seguro-Desemprego. Disponível em: https://bit.ly/2ZtuOPI. Acesso em: 15 jul. 2020.

BRASIL. Constituição da República Federativa do Brasil de 1988. Disponível em: https://bit.ly/3j9iDiX. Acesso em: 15 jul. 2020.

BRASIL. Decreto 8.424, de 31 de março de 2015. Regulamenta a Lei no 10.779, de 25 de novembro de 2003, para dispor sobre a concessão do benefício de seguro-desemprego, durante o período de defeso, ao pescador profissional artesanal que exerce sua atividade exclusiva e ininterruptamente. Disponível em: https://bit.ly/2CidiFl. Acesso em: 15 jul. 2020.

BRASIL. Lei 10.779, de 25 de novembro de 2003. Dispõe sobre a concessão do benefício de seguro desemprego, durante o período de defeso, ao pescador profissional que exerce a atividade pesqueira de forma artesanal. Disponível em: https://bit.ly/2Or8Num. Acesso em: 15 jul. 2020.

BRASIL. Lei 13.846, de 18 de junho de 2019. Institui o Programa Especial para Análise de Benefícios com Indícios de Irregularidade, o Programa de Revisão de Benefícios por Incapacidade, o Bônus de Desempenho Institucional por Análise de Benefícios com Indícios de Irregularidade do Monitoramento Operacional de Benefícios e o Bônus de Desempenho Institucional por Perícia Médica em Benefícios por Incapacidade; altera as Leis nos 6.015, de 31 de dezembro de 1973, 7.783, de 28 de junho de 1989, 8.112, de 11 de dezembro de 1990, 8.212, de 24 de julho de 1991, 8.213, de 24 de julho de 1991, 8.742, de 7 de dezembro de 1993, 9.620, de 2 de abril de 1998, 9.717, de 27 de novembro de 1998, 9.796, de 5 de maio de 1999, 10.855, de $1^{\circ}$ de abril de 2004, 10.876, de 2 de junho de 2004, 10.887, de 18 de junho de 2004, 11.481, de 31 de maio de 2007, e 11.907, de 2 de fevereiro de 2009; e revoga dispositivo da Lei $\mathrm{n}^{\circ} 10.666$, de 8 de maio de 2003, e a 
Lei $\mathrm{n}^{\circ}$ 11.720, de 20 de junho de 2008. Disponível em: https://bit.ly/2DPaeB7. Acesso em: 15 jul. 2020.

BRASIL. Lei 7.998, de 11 de janeiro de 1990. Regula o Programa do Seguro-Desemprego, o Abono Salarial, institui o Fundo de Amparo ao Trabalhador (FAT), e dá outras providências. Disponível em: https://bit.ly/3fADidi. Acesso em: 15 jul. 2020.

BRASIL. Lei 8.213, de 24 de julho de 1991. Dispõe sobre os Planos de Benefícios da Previdência Social e dá outras providências. Disponível em: https://bit.ly/38Xdfuw. Acesso em: 15 jul. 2020.

BRASIL. Lei Complementar 150, de $1^{\mathbf{0}}$ de junho de 2015. Dispõe sobre o contrato de trabalho doméstico; altera as Leis $\mathrm{n}^{0}$ 8.212, de 24 de julho de 1991, nํㅛ 8.213, de 24 de julho de 1991, e $\mathrm{n}^{\mathrm{0}}$ 11.196, de 21 de novembro de 2005; revoga o inciso I do art. $3^{\circ}$ da Lei $\mathrm{n}^{\circ} \mathrm{8.009}$, de 29 de março de 1990, o art. 36 da Lei no 8.213, de 24 de julho de 1991, a Lei no 5.859, de 11 de dezembro de 1972, e o inciso VII do art. 12 da Lei no 9.250, de 26 de dezembro 1995; e dá outras providências. Disponível em: https://bit.ly/3eEKNPr. Acesso em: 15 jul. 2020.

BRASIL. Superior Tribunal de Justiça. AgInt no REsp 1863526/RS. Agravante: Marcelo Rocha Kerber. Agravada: União. 2a Turma. Relator: Ministro Herman Benjamin, Brasília, DF, 8 jun. 2020. Diário da Justiça Eletrônico, Brasília, DF, 16 jun. 2020a. Disponível em: https://bit.ly/3gZX8PB. Acesso em: 15 jul. 2020.

BRASIL. Superior Tribunal de Justiça. AREsp 1541138/SP. Agravante: Fazenda Nacional. Agravado: EMC Computer Systems Brasil Ltda. $2^{\text {a }}$ Turma. Relator: Ministro Herman Benjamin, Brasília, DF, 5 dez. 2019. Diário de Justiça Eletrônico, Brasília, DF, 19 dez. 2019f. Disponível em: https://bit.ly/3fyTRGv. Acesso em: 15 jul. 2020.

BRASIL. Superior Tribunal de Justiça. REsp 1174034/RS. Recorrente: União. Recorrido: Luciano Vargas dos Santos. Relator: Ministro Castro Meira, Brasília, DF, 24 fev. 2010. Diário de Justiça da União, Brasília, DF, 25 fev. 2010. Disponível em: https://bit.ly/2Won2EP. Acesso em: 15 jul. 2020.

BRASIL. Superior Tribunal de Justiça. REsp 1723181/RS. Recorrente: INSS. Recorrido: Delcio de Araújo Gabbi. $1^{a}$ Seção. Relator: Ministro Napoleão Nunes Maia Filho, Brasília, DF, 26 jun. 2019. Diário de Justiça Eletrônico, Brasília, DF, 1 ago. 2019g. Disponível em: https://bit.ly/2WqzdB8. Acesso em: 15 jul. 2020.

BRASIL. Superior Tribunal de Justiça. REsp 1794629/SP. Recorrente: Sul América Companhia de Seguro Saúde. Recorridos: Lilian Fernanda da Silva Baroli e outro. $3^{\mathrm{a}}$ Turma. Relatora para o Acórdão: Ministra Nancy Andrighi, Brasília, DF, 18 fev. 2020. Diário de Justiça Eletrônico, Brasília, DF, 10 mar. 2020g. Disponível em: https://bit.ly/2Opec5i. Acesso em: 15 jul. 2020.

BRASIL. Superior Tribunal de Justiça. REsp 1799876/RS. Recorrente: União. Recorrido: José Luís Barbosa dos Santos. Relatora: Ministra Regina Helena Costa, Brasília, DF, 28 mar. 2019. Diário de Justiça Eletrônico, Brasília, DF, 3 abr. 2019a. Disponível: https://bit.ly/32pumDV. Acesso em: 15 jul. 2020.

BRASIL. Superior Tribunal de Justiça. REsp 1810536/PR. Recorrente: União. Recorrida: Eleni Constante Vieira. $2^{\text {a }}$ Turma. Relator: Ministro Herman Benjamin, Brasília, DF, 5 set. 2019. Diário 
de Justiça Eletrônico, Brasília, DF, 11 out. 2019b. Disponível em: https://bit.ly/2C6n39H. Acesso em: 15 jul. 2020.

BRASIL. Superior Tribunal de Justiça. REsp 653134/PR. Recorrente: União. Recorrida: Candice Regina David. $2^{\text {a }}$ Turma. Relator: Ministro Franciulli Netto, Brasília, DF, 2 ago. 2005. Diário de Justiça da União, Brasília, DF, 12 set. 2005. Disponível em: https://bit.ly/32pumDV. Acesso em: 15 jul. 2020.

BRASIL. Supremo Tribunal Federal. AC 1033 AgR-QO. Agravante: União. Agravados: Estado do Amazonas e outros. Plenário. Relator: Ministro Celso de Mello, Brasília, DF, 25 maio 2006. Diário da Justiça, Brasília, DF, 16 jun. 2006. Disponível em: https://bit.ly/393Z075. Acesso em: 15 jul. 2020.

BRASIL. Supremo Tribunal Federal. ADI 5127/DF. Requerente: CNPL. Plenário. Relator para o Acórdão: Ministro Edson Fachin, Brasília, DF, 15 out. 2015. Diário de Justiça Eletrônico, 11 maio 2016c. Disponível em: https://bit.ly/3j0sF5I. Acesso em: 15 jul. 2020.

BRASIL. Supremo Tribunal Federal. ARE 904929 AgR/SP. Agravante: CREF4/SP. Agravado: Edmar Donizeti Amancio Tristao. 2a Turma. Relatora: Ministra Cármen Lúcia, Brasília, DF, 13 out. 2015. Diário de Justiça Eletrônico, Brasília, DF, 3 nov. 2015a. Disponível em: https://bit.ly/32l55Lh. Acesso em: 15 jul. 2020.

BRASIL. Supremo Tribunal Federal. HC 85060/PR. Paciente: Divonzir Catenace. Coator: STJ. $1^{\mathrm{a}}$ Turma. Relator: Ministro Eros Grau, Brasília, DF, 23 set. 2008. Diário de Justiça Eletrônico, Brasília, DF, 13 fev. 2009. Disponível em: https://bit.ly/3j4qQVn. Acesso em: 15 jul. 2020.

BRASIL. Supremo Tribunal Federal. MS 25838/DF. Impetrante: Associação Nacional dos Procuradores da República. Impetrados: TCU e PGR. $2^{\mathrm{a}}$ Turma. Relator: Ministro Teori Zavascki, Brasília, DF, 29 set. 2015. Diário de Justiça Eletrônico, Brasília, DF, 13 out. 2015b. Disponível em: https://bit.ly/2OtLOz8. Acesso em: 15 jul. 2020.

BRASIL. Supremo Tribunal Federal. RE 626489/SE. Recorrente: INSS. Recorrida: Maria das Dores Oliveira Martins. Plenário. Relator: Ministro Roberto Barroso, Brasília, DF, 16 out. 2013. Diário da Justiça Eletrônico, Brasília, DF, 23 set. 2014. Disponível em: https://bit.ly/3fzRZxj. Acesso em: 15 jul. 2020.

BRASIL. Tribunal Regional Federal da $1^{\text {a }}$ Região. EDAC 00208094820074013800. Apelante: União. Apelada: Janete Silva Braga. $2^{a}$ Turma. Relator para o Acórdão: Desembargador Federal João Luiz de Sousa, Brasília, DF, 6 dez. 2017. Diário Eletrônico da Justiça Federal da $1^{\text {a }}$ Região, Brasília, DF, 23 jan. 2018b. Disponível em: https://bit.ly/3fC4UyQ. Acesso em: 15 jul. 2020.

BRASIL. Tribunal Regional Federal da $1^{a}$ Região. ReeNec 10006002520184013810. Recorrente: Juscelia Passos Feliciano Souza. Recorrida: União. $1^{\text {a }}$ Turma. Relator: Desembargador Federal Wilson Alves de Souza, Brasília, DF, 3 jun. 2020. Diário Eletrônico da Justiça Federal da $1^{\text {a }}$ Região, Brasília, DF, 9 jun. 2020b. Disponível em: https://bit.ly/3j8JgVd. Acesso em: 15 jul. 2020.

BRASIL. Tribunal Regional Federal da $2^{\mathrm{a}}$ Região. Agravo de Instrumento 00027869220184020000. Agravante: União. Agravada: Marcela Moreira Paraizo. $6^{\text {a }}$ Turma Especializada. Relator: Desembargador Federal Guilherme Calmon Nogueira da Gama, Rio de 


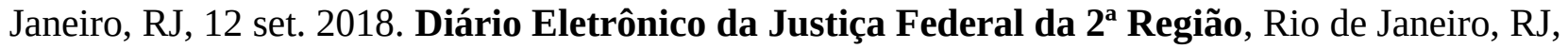
21 set. 2018c. Disponível em: https://bit.ly/3j6OBw9. Acesso em: 15 jul. 2020.

BRASIL. Tribunal Regional Federal da 2a Região. AI 00543937520154025101. Agravante: União. Agravada: Thais Bustilho da Silva. $1^{\text {a }}$ Turma Especializada. Relator: Juiz Federal Convocado Gustavo Arruda Macedo, Rio de Janeiro, RJ, 3 maio 2018. Diário Eletrônico da Justiça Federal da $2^{\text {a }}$ Região, Rio de Janeiro, RJ, 7 maio 2018f. Disponível em: https://bit.ly/3ewaxxf. Acesso em: 15 jul. 2020.

BRASIL. Tribunal Regional Federal da 2a Região. Apelação Cível/Reexame Necessário 00578493320154025101. Apelante: União. Apelado: Mauro César Casamasso da Fonseca. $2^{\mathrm{a}}$ Turma Especializada. Relatora: Desembargadora Federal Simone Schreiber, Rio de Janeiro, RJ, 21 out. 2019. Diário Eletrônico da Justiça Federal da $2^{a}$ Região, Rio de Janeiro, RJ, 3 dez. 2019d. Disponível em: https://bit.ly/3ewk2wg. Acesso em: 15 jul. 2020.

BRASIL. Tribunal Regional Federal da 2a Região. REOMS 00161737120164025101. Autor: Joselito da Costa Martins. Ré: União. $5^{\text {a }}$ Turma Especializada. Relator: Desembargador Federal Aluisio Gonçalves de Castro Mendes, Rio de Janeiro, RJ, 27 nov. 2018. Diário Eletrônico da Justiça Federal da $2^{\text {a }}$ Região, Rio de Janeiro, RJ, 4 dez. 2018d. Disponível em: https://bit.ly/2ZxRnTn. Acesso em: 15 jul. 2020.

BRASIL. Tribunal Regional Federal da $2^{\text {a }}$ Região. REOMS 00543937520154025101. Autor: Joselito da Costa Martins. Ré: União. $7^{\mathrm{a}}$ Turma Especializada. Relator: Desembargador Federal José Antonio Neiva, Rio de Janeiro, RJ, 22 jun. 2018. Diário Eletrônico da Justiça Federal da $2^{a}$ Região, Rio de Janeiro, RJ, 27 jun. 2018e. Disponível em: https://bit.ly/38YOzSl. Acesso em: 15 jul. 2020.

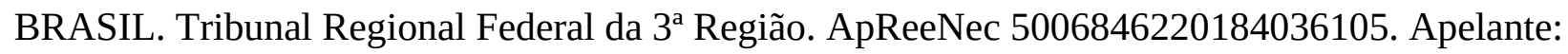
União. Apelado: Jaime Andrade Santos. 10a Turma. Relator: Desembargador Federal Nelson de Freitas Porfírio Júnior, São Paulo, SP, 5 mar. 2020. Diário Eletrônico da Justiça Federal da $3^{\text {a }}$ Região, São Paulo, SP, 13 mar. 2020c. Disponível em: https://bit.ly/2B0tjyX. Acesso em: 15 jul. 2020.

BRASIL. Tribunal Regional Federal da 3ª Região. RemNecCiv 50048520620184036119. Autor: Oswaldo Leonardo. Ré: União. $8^{a}$ Turma. Relator: Desembargador Federal David Diniz Dantas, São Paulo, SP, 25 set. 2019. Diário Eletrônico da Justiça Federal da $3^{\text {a }}$ Região, São Paulo, SP, 27 set. 2019c. Disponível em: https://bit.ly/2B0tjyX. Acesso em: 15 jul. 2020.

BRASIL. Tribunal Regional Federal da 3ª Região. RemNecCiv 50066070420174036183. Autor: Ismael Corte Inácio Júnior. Ré: União. $7^{\mathrm{a}}$ Turma. Relator: Desembargador Federal Carlos Eduardo Delgado, São Paulo, SP, 29 jan. 2020. Diário Eletrônico da Justiça Federal da $3^{\text {a }}$ Região, São Paulo, SP, 31 jan. 2020d. Disponível em: https://bit.ly/2B0tjyX. Acesso em: 15 jul. 2020.

BRASIL. Tribunal Regional Federal da $4^{\mathrm{a}}$ Região. AC 50083805120194047003. Apelante: Jhonny da Silva Avila. Apelado: União. $3^{a}$ Turma. Relator: Desembargador Federal Rogério Favreto, Porto Alegre, RS, 7 jul. 2020. Diário Eletrônico da Justiça Federal da $4^{\text {a }}$ Região, Porto Alegre, RS, 7 jul. 2020e. Disponível em: https://bit.ly/2OsjQnd. Acesso em: 15 jul. 2020. 
BRASIL. Tribunal Regional Federal da 4ª Região. AC 550041322120194047010. Apelante: Antonio Marques dos Santos. Apelado: União. $4^{\mathrm{a}}$ Turma. Relator: Desembargador Federal Ricardo Teixeira do Valle Pereira, Porto Alegre, RS, 1 jul. 2020. Diário Eletrônico da Justiça Federal da

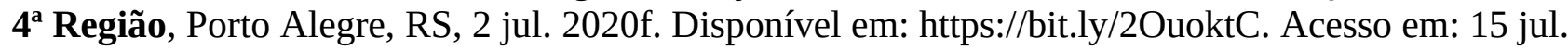
2020.

BRASIL. Tribunal Regional Federal da 5a Região. AC 00003525220114058000. Apelante: União. Apelado: Fábio Alberto Lima da Costa. $2^{\mathrm{a}}$ Turma. Relator: Desembargador Federal Sérgio Murilo Wanderley Queiroga (Convocado), Recife, PE, 23 out. 2012. Diário Eletrônico da Justiça Federal

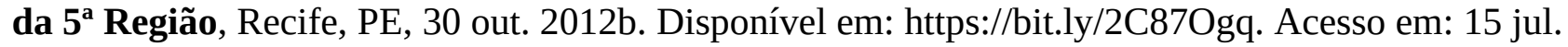
2020.

BRASIL. Tribunal Regional Federal da $5^{\text {a }}$ Região. AC 08000158320184058000. Apelante: União. Apelado: Maria Aparecida da Silva. $4^{\mathrm{a}}$ Turma. Relator: Desembargador Federal Rubens de Mendonça Canuto, Recife, PE, 30 nov. 2018. Diário Eletrônico da Justiça Federal da $5^{\mathbf{a}}$ Região, Recife, PE, 30 nov. 2018g. Disponível em: https://bit.ly/2ZyXaIu. Acesso em: 15 jul. 2020.

BRASIL. Tribunal Regional Federal da 5a Região. APELREEX 08006788520164058102. Apelante: União. Apelado: Maria Gleiciane Ferreira Melo. $3^{\text {a }}$ Turma. Relator: Desembargador Federal Carlos Rebêlo Júnior, Recife, PE, 22 maio 2018. Diário Eletrônico da Justiça Federal da

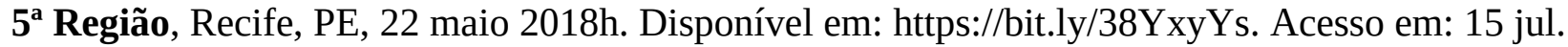
2020.

BRASIL. Tribunal Regional Federal da 5a Região. APELREEX 08057946820184058404. Apelante: União. Apelado: Stefania Pinheiro Guerra Pereira. $1^{a}$ Turma. Relator: Desembargador Federal Élio Wanderley de Siqueira Filho, Recife, PE, 30 nov. 2019. Diário Eletrônico da Justiça Federal da $5^{\text {a }}$ Região, Recife, PE, 30 nov. 2019e. Disponível em: https://bit.ly/3h3uNIi. Acesso em: 15 jul. 2020.

BRASIL. Turma Nacional de Uniformização de Jurisprudência dos Juizados Especiais Federais. PEDILEF 200850500029940. Relator: Juiz Federal Alcides Saldanha Lima, Brasília, DF, 27 jun. 2012. Diário Oficial da União, Brasília, DF, 27 jul. 2012a, p. 105/204.

BRASIL. Turma Nacional de Uniformização de Jurisprudência dos Juizados Especiais Federais. PEDILEF 50053009820144047215. Requerente: União. Requerido: Alisson Antonio Parra. Relatora: Juíza Federal Cármen Elizangela Dias Moreira de Resende, Brasília, DF, 22 mar. 2018. E-Proc, Brasília, DF, 3 abr. 2018a. Disponível em: https://bit.ly/3gZCuiw. Acesso em: 15 jul. 2020.

CAIRO JR., José. Curso de direito do trabalho: direito individual e coletivo do trabalho. 16. ed. Salvador: Ed. JusPodivm, 2019.

DEMO, Roberto Luis Luchi; SOMARIVA, Maria Salute. Benefícios previdenciários e seu regime jurídico: salário-família, salário-maternidade, auxílio-reclusão e seguro-desemprego. Âmbito Jurídico, [s. l.], 31 maio 2006. Disponível em: https://bit.ly/3exokDw. Acesso em: 14 jul. 2020.

FARIAS, Edilsom. Restrição de direitos fundamentais. Sequência, [s. l.], vol. 21, n. 41, 2000.

GOMES CANOTILHO, José Joaquim. Direito Constitucional e Teoria da Constituição. 7. ed. Coimbra: Livraria Almedina, 1993. 
KELSEN, Hans. Teoria geral das normas. Tradução José Florentino Duarte. Porto Alegre: Sergio Antonio Fabris Editor, 1986.

KELSEN, Hans. Teoria pura do direito. Trad. João Baptista Machado. 6. ed. São Paulo: Martins Fontes, 1998.

LEITE, Carlos Henrique Bezerra. Curso de direito do trabalho. 11. ed. São Paulo: Ed. Saraiva, 2019a.

LEITE, Carlos Henrique Bezerra. Curso de direito processual do trabalho. 17. ed. São Paulo: Ed. Saraiva, 2019b.

MARTINEZ, Luciano. Curso de direito do trabalho. 11. ed. São Paulo: Ed. Saraiva, 2020.

MELLO, Celso Antônio Bandeira de. Curso de Direito Administrativo. 13. ed. São Paulo: Ed. Malheiros, 2001.

MERKL, Adolf. Prolegómenos a una teoría de la estructura jurídica escalonada del ordenamiento (I). Revista de Derecho Constitucional Europeo, [s. l.], n. 2, 2004.

MERKL, Adolf. Prolegómenos a una teoría de la estructura jurídica escalonada del ordenamiento (II). Revista de Derecho Constitucional Europeo, [s. l.], n. 3, 2005.

MOURA, Marcelo. Curso de direito do trabalho. 2. ed. São Paulo: Ed. Saraiva, 2016.

NASCIMENTO, Amauri Mascaro. Curso de direito do trabalho. 29. ed. São Paulo: Ed. Saraiva, 2014.

PAMPLONA FILHO, Rodolfo. Curso de direito processual do trabalho. 2. ed. São Paulo: Ed. Saraiva, 2020.

RAZ, Joseph. Kelsen's theory of the basic norm. American Journal of Jurisprudence, [s. l.], vol. 19, 1974.

ROBLES, Gregorio. Consideraciones sobre la teoría de la norma jurídica en Kelsen. Estudios de Deusto, [s. l.], vol. 30, n. 1, 1982.

ROMAR, Carla Teresa Martins. Direito do trabalho esquematizado. 5. ed. São Paulo: Ed. Saraiva, 2018.

SOUZA JÚNIOR, Antonio Umberto de. O novo direito do trabalho doméstico. São Paulo: Ed. Saraiva, 2015.

WALTER, Robert. Origen y desarrollo del concepto de norma fundamental. Revista de la Facultad de Derecho de México, [s. l.], n. 244, 2005. 
Julio Pinheiro Faro Homem de Siqueira

Mestre em Direitos e Garantias Fundamentais

9Lattes iD: http://lattes.cnpq.br/1936096236504255

E-mail: julio.pfhs@gmail.com

Victor Roberto Corrêa de Souza

Doutor em Ciências Jurídicas e Sociais

9Lattes iD: http://lattes.cnpq.br/3920381802806264

E-mail: victor_souzarj@yahoo.com.br 